\title{
Electrochemical Synthesis and Studies of Polypyrroles Doped by Renewable Dopant Cardanol Azophenylsulfonic Acid Derived from Cashew Nutshells
}

\author{
S. Radhakrishan, Chepuri R. K. Rao, M. Vijayan \\ Functional Materials Division, Central Electrochemical Research Institute, Karaikudi 630 006, India
}

Received 8 July 2008; accepted 28 May 2009

DOI 10.1002/app.30900

Published online 28 July 2009 in Wiley InterScience (www.interscience.wiley.com).

\begin{abstract}
The raw material cardanol, a renewable resource, is industrial waste and a pollutant from the cashew nut industry. Cardanol is a useful starting material for synthesizing a new amphiphilic molecule, cardanol azophenylsulfonic acid (CAPSA). In this study, polypyrroles were electrochemically synthesized with the renewable dopant CAPSA. The polymers were characterized with ultraviolet-visible, Fourier transform infrared, conductivity,
\end{abstract}

impedance, charge-discharge, and cyclic voltammetry analyses. The conductivity of the films doped by CAPSA was in the range of $1.23-3.98 \times 10^{-5} \mathrm{~S} / \mathrm{cm}$, and they exhibited moderate specific capacitance values. (02009 Wiley Periodicals, Inc. J Appl Polym Sci 114: 3125-3131, 2009

Key words: conducting polymers; electrochemistry; films; FT-IR; polypyrroles

\section{INTRODUCTION}

Intrinsically conducting polymers now have a special status after pioneering and Noble prize winning work in the year 2000 by Shirakawa et al. ${ }^{1}$ Soon after this, many new conducting polymers, called synthetic metals, were discovered, such as polyaniline, polypyrrole (PPy), and polythiophene. ${ }^{2}$ Conducting polymers are excellent candidates for applications in displays, electrochromic mirrors, windows, lightemitting diodes, photovoltaics, near-infrared devices, and electrochromic devices. ${ }^{3}$

Among conducting polymers, PPy is one of the most studied materials. The usefulness of this polymer has been realized because this material exhibits a number of interesting properties, including reversible redox activity, ${ }^{4}$ an ability to form thin films and nanowires with room-temperature conductivity ranging from $10^{-4}$ to $10^{-2} \mathrm{~S} / \mathrm{cm},{ }^{5}$ ion-exchange/iondiscrimination properties, ${ }^{6,7}$ electrochromic effects and charge/discharge processes, ${ }^{8}$ strong absorptive properties toward gases, ${ }^{9}$ proteins, ${ }^{10}$ and DNA, ${ }^{11}$ catalytic activity, ${ }^{12-14}$ and corrosion protection properties. ${ }^{15}$ Recent studies on the polymer have focused on sensors for many biologically important molecules, drug delivery, ${ }^{16,17}$ and charge-storage devices (particularly as a supercapacitor material). ${ }^{18-20}$

The raw material cardanol, a renewable resource (Fig. 1), is industrial waste and a pollutant from the cashew nut industry. Cardanol is a useful starting

Correspondence to: M. Vijayan (vijayan59@gmail.com).

Journal of Applied Polymer Science, Vol. 114, 3125-3131 (2009) (C) 2009 Wiley Periodicals, Inc. material for synthesizing a new amphiphilic molecule, cardanol azophenylsulfonic acid (CAPSA; Fig. 1). ${ }^{21}$ The sulfonic acid molecule has been employed as a dopant for polyaniline nanomaterials, and various properties of polyaniline nanomaterials have been studied. ${ }^{22,23}$ The aim of this work was to synthesize PPy electrochemically with the renewable dopant CAPSA and study its use as a material for supercapacitors.

\section{EXPERIMENTAL}

\section{Methods and materials}

The renewable dopant CAPSA was supplied by the National Institute for Interdisciplinary Science and Technology (Trivandrum, India) and was reported to be synthesized according to the published procedure. ${ }^{21} X$-ray diffraction patterns were obtained with a PANalytical (The Netherlands) MPD diffractometer with $\mathrm{Cu} \mathrm{K} \alpha$ radiation. Fourier transform infrared (FTIR) spectra of the samples (with KBr powder pellets) were recorded on a Paragon 500 spectrometer from PerkinElmer (USA). The conductivity of the polymer films was measured by the four-probe method with a Keithley (USA) nanovoltmeter. Thermogravimetric analysis (TGA) experiments were performed with a TA instruments (UK) model SDT Q600 via heating under air at $20^{\circ} \mathrm{C} / \mathrm{min}$. Atomic force microscopy was carried out on a Molecular Imaging instrument in the constant-distance mode. Ultraviolet-visible (UV-vis) spectra were recorded on a Cary 500 Scan UV-vis spectrophotometer (USA) in the reflectance mode. 
(a)<smiles>[R]c1cccc(O)c1</smiles><smiles>[R]c1cc(O)ccc1N=Nc1ccc(S(=O)(=O)O)cc1</smiles>

CARDANOL

$\mathbf{R}$<smiles>[Z]#CCCCCCCC=CCCCCCC</smiles>

(b)

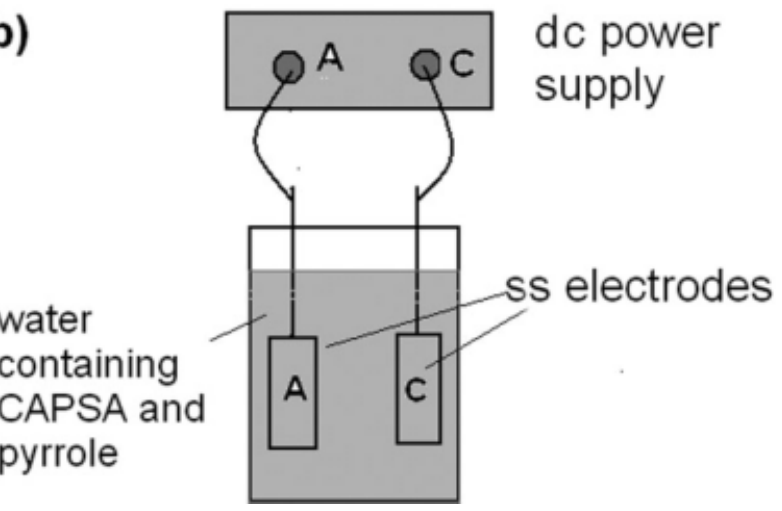

Figure 1 (a) Chemical structures of cardanol and CAPSA and (b) schematic diagram of the synthesis of large and thick PPy films ( $\mathrm{dc}=$ direct current; ss = stainless steel).

\section{Electrochemical studies}

Cyclic voltammetry (CV) experiments were performed on an Autolab 302 (The Netherlands) electrochemical system using a three-electrode assembly. A $2 \mathrm{~mm} \times 2.5 \mathrm{~mm}$ piece of platinum foil (or a $1-\mathrm{cm}^{2}$ stainless steel electrode for charge-discharge studies) and a glassy carbon rod $(2 \mathrm{~mm}$ in diameter and $8 \mathrm{~cm}$ long) were used as the working and counter electrodes. A saturated calomel electrode (SCE) was used as the reference electrode. A Solartron (UK) model SI 1287 electrochemical analyzer with a model SI 1260 impedance analyzer was used for impedance measurements. Thin PPy films (ca. $0.1 \mu \mathrm{m}$ ) were obtained through the cycling of the potential between -0.2 and $1.2 \mathrm{~V}$ for several cycles. To increase the thickness and area of the films $(>2 \mu \mathrm{m}$ and $2.54 \mathrm{~cm} \times 2.54 \mathrm{~cm})$, the anodic deposition of the films was conducted in a 100-mL glass beaker on stainless steel electrodes with an APLAB (India) model LD 3205 direct-current power supply unit (32 V and $5 \mathrm{~A}$ ) with an applied cell voltage of $1.5 \mathrm{~V}$ [as shown in Fig. 1(b)]. The films on stainless steel were subjected to impedance analysis in a $1 \mathrm{M} \mathrm{KCl}$ aqueous solution.

\section{RESULTS AND DISCUSSION}

In this investigation, CAPSA [Fig. 1(a)], derived from cardanol, was used as an electrolyte and dopant for the electrochemical synthesis of PPy.
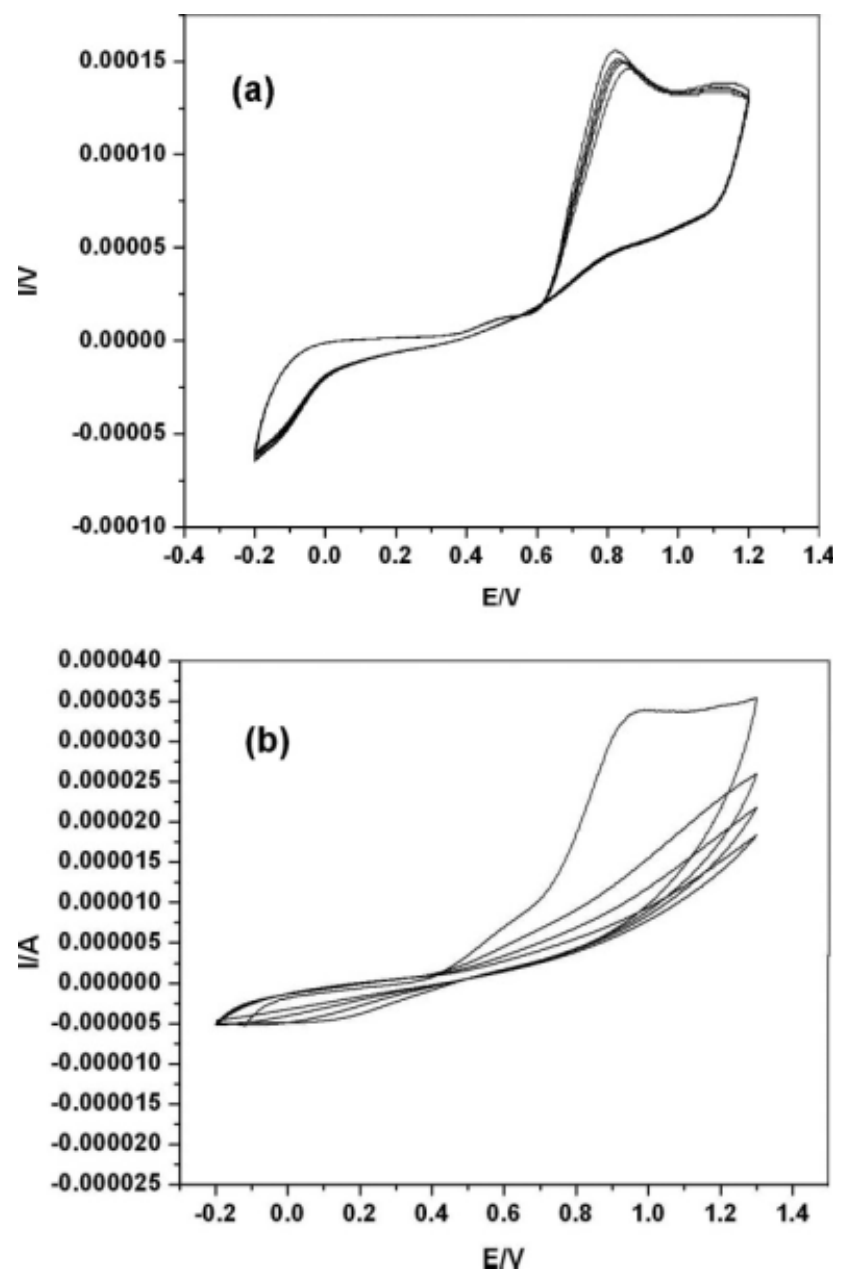

Figure 2 Growth of (a) PPy and (b) P(NMePy) in 0.5M aqueous solutions of CAPSA at a Pt electrode (scan rate $=$ $50 \mathrm{mV} / \mathrm{s})$.

Cardanol is a phenolic compound containing an unsaturated $\mathrm{C}_{15}$ alkyl chain at the meta position and is available largely as waste from the cashew nut

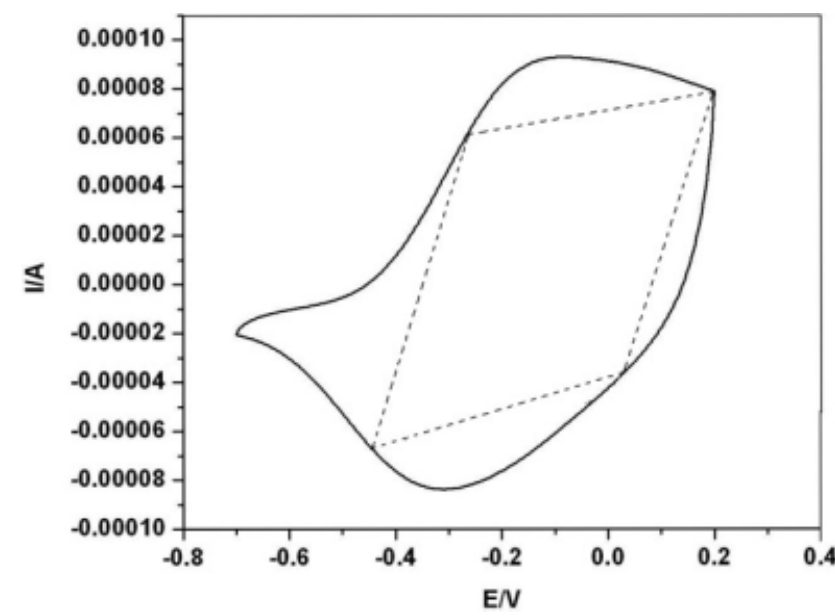

Figure 3 Doping-dedoping process exhibited by PPyCAPSA deposited on a Pt electrode in a $1 \mathrm{M} \mathrm{KCl}$ solution at a scan rate of $50 \mathrm{mV} / \mathrm{s}$. 

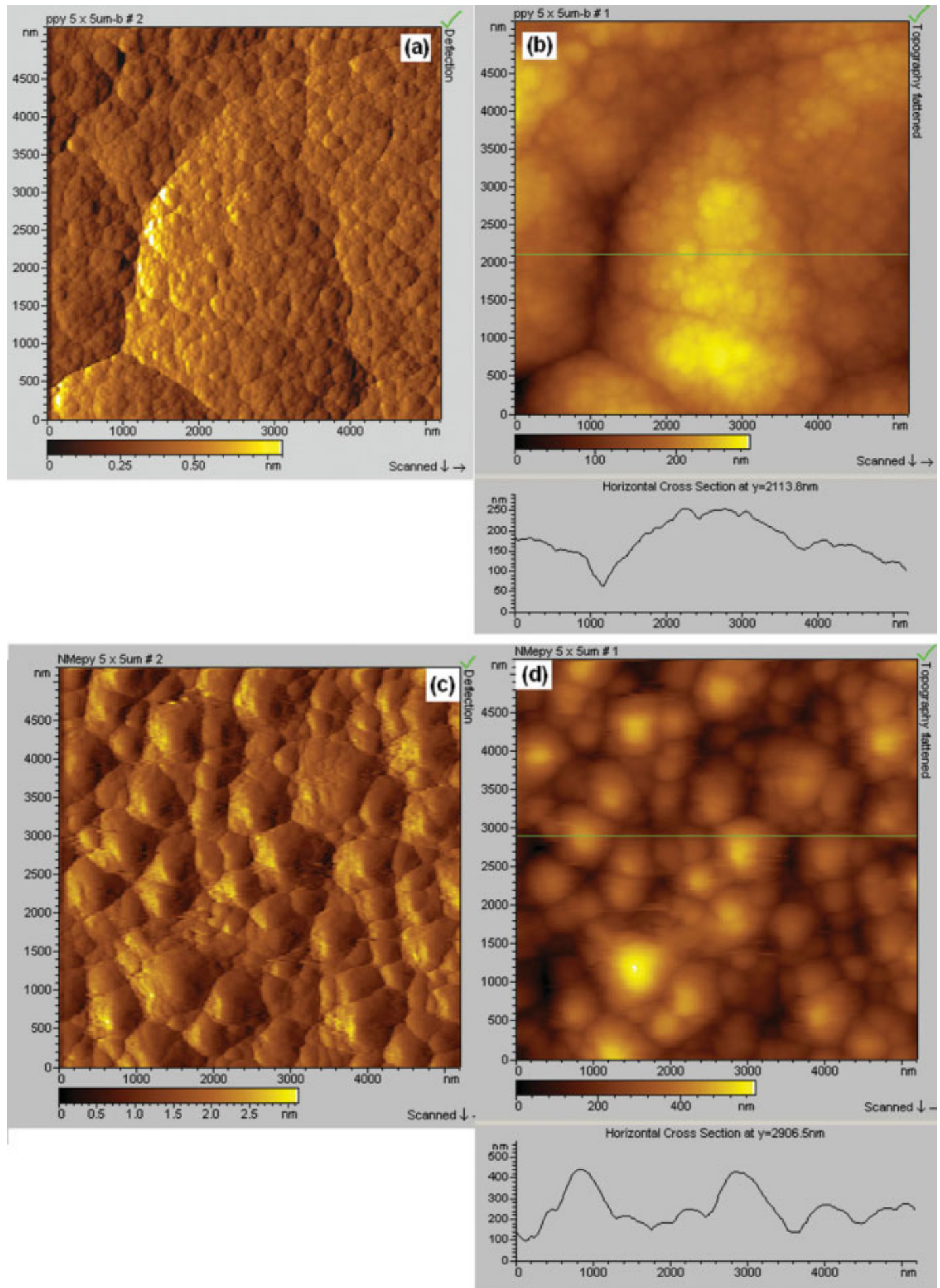

Figure 4 Atomic force microscopy analysis of the polymers: (a) surface and (b) cross sections of a PPy-CAPSA film and (c) surface and $(\mathrm{d})$ cross sections of a P(NMePy)-CAPSA film on a stainless steel electrode. [Color figure can be viewed in the online issue, which is available at www.interscience.wiley.com.]

industry. The direct synthesis of a sulfonic acid derivative from cardanol is not possible by sulfonation at the phenyl ring because of the presence of an unsaturated double bond in the pendent long chain, and hence the synthesis of CAPSA was carried out by diazotization of $p$-aminobenzene sulfonic acid and cardanol. ${ }^{21}$ The dopant CAPSA has an amphiphilic group in which the hydrophilic sulfonic acid part behaves as a polar head, and the long alkyl chain behaves as a hydrophobic tail. The free 


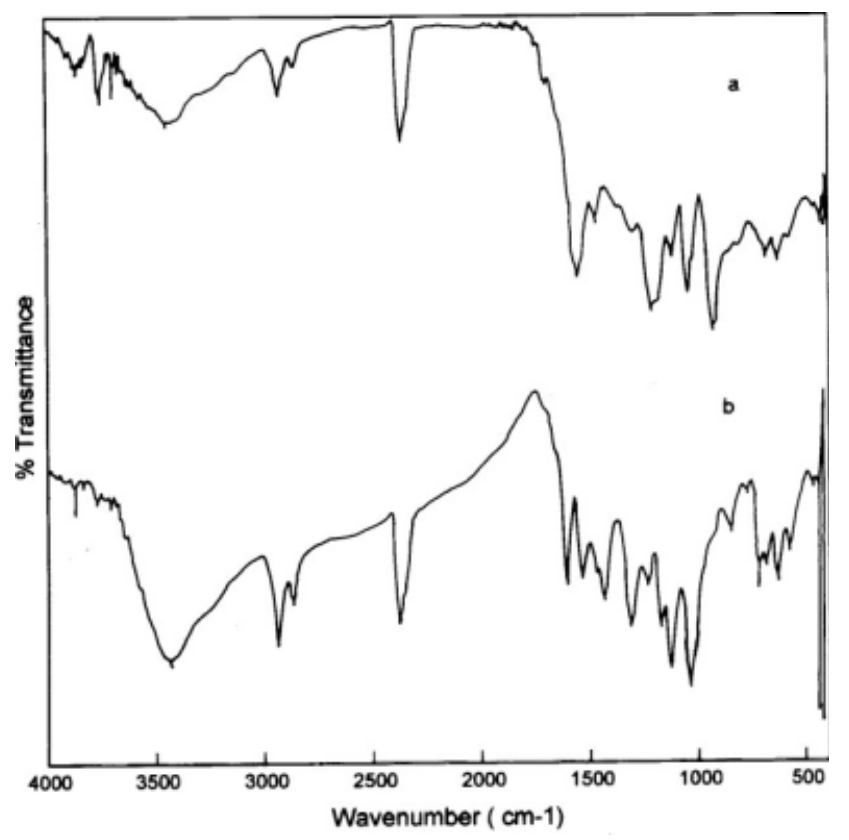

Figure 5 FTIR spectra of (a) PPy-CAPSA and (b) $\mathrm{P}(\mathrm{NMePy})-\mathrm{CAPSA}$ recorded as $\mathrm{KBr}$ pellets.

phenolic group $(-\mathrm{OH})$ may also provide hydrogenbonding interactions with the PPy backbone. ${ }^{21}$ The dopant CAPSA is freely soluble in water and is advantageous for preparing PPy electrochemically in water.

\section{Electrochemical synthesis and characterization}

The electrochemical synthesis of PPy and poly $(N-$ methylpyrrole) $[\mathrm{P}(\mathrm{NMePy})]$ was carried out with a potentiostat through the cycling of the potential between -0.2 and 1.2 (Fig. 2) in a $0.5 \mathrm{M}$ aqueous solution of CAPSA on a 2-mm-diameter platinum disc electrode. $\mathrm{CV}$ showed radical cation formation at $0.87 \mathrm{~V}$ in the first scan [Fig. 2(a)]; 15 more scans were performed to build up the polymer layer. According to the numerical calculations based on the charge consumed in the electropolymerization reaction of pyrrole $\left(500 \mathrm{mC} / \mathrm{cm}^{2}\right.$ gave an approximately $1-\mu$ m-thick PPy film), ${ }^{24,25}$ the thickness of the film formed on the platinum disc was $0.10 \mu \mathrm{m}$. After 15 cycles, the electrode was taken from the monomer solution, washed with water, and further investigated by $\mathrm{CV}$. The doping/dedoping characteristics were explored in a $1 M \mathrm{KCl}$ solution. The doping/ dedoping process was broad (Fig. 3), extending into a wide potential range of -0.6 to $+0.2 \mathrm{~V}$. The process was characterized by a broad anodic peak centered at $-0.175 \mathrm{~V}$ and a similar broad reduction peak centered at $-0.3 \mathrm{~V}$. This is in contrast to PPy doped/dedoped by small anions in the literature. ${ }^{26}$ The broad doping-dedoping cyclic voltammogram involving a higher current suggested that the polymer could be a useful material for electrochemical supercapacitors. The symmetric parallelogram shape that could be fit into the cyclic voltammogram also indicated a supercapacitor nature. Under similar experimental conditions of doping/dedoping, $\mathrm{P}(\mathrm{NMePy})-\mathrm{CAPSA}$ films showed a sharper oxidation peak at $+0.223 \mathrm{~V}$ and a reduction peak at -0.4 $\mathrm{V}$ with the involvement of a lower current. This difference suggests that doping/dedoping of CAPSA molecules in the $\mathrm{N}$-methyl-substituted polymer is more difficult and may also involve the ingression of $\mathrm{Cl}^{-}$ions for charge neutrality. ${ }^{26}$

The morphology of the film obtained with the CV method, as determined with atomic force microscopy, is shown in Figure 4. For PPy-CAPSA, the surface had a cauliflower-globular-type morphology with sizes ranging from 50 to $200 \mathrm{~nm}$. These structures are more grown in size for P(NMePy)-CAPSA and are typically in the range of $200-500 \mathrm{~nm}$.

To obtain larger amounts of electropolymerized materials, scale-up electrolysis was carried out with a $100-\mathrm{mL} 1 \mathrm{M}$ CAPSA solution containing $0.1 \mathrm{M}$ pyrrole(or $\mathrm{N}$-methylpyrrole) on stainless steel electrodes. The thick, fragile films obtained after $0.5 \mathrm{~h}$ of polymerization were taken from the electrode and subjected to spectral investigations. The FTIR spectrum (Fig. 5) of the polymers showed charge carriers, bipolaron bands at 921.6 and $1207.9 \mathrm{~cm}^{-1}$, indicating that the PPy which formed was in an oxidized state. ${ }^{27,28}$ The peaks between 1551 and
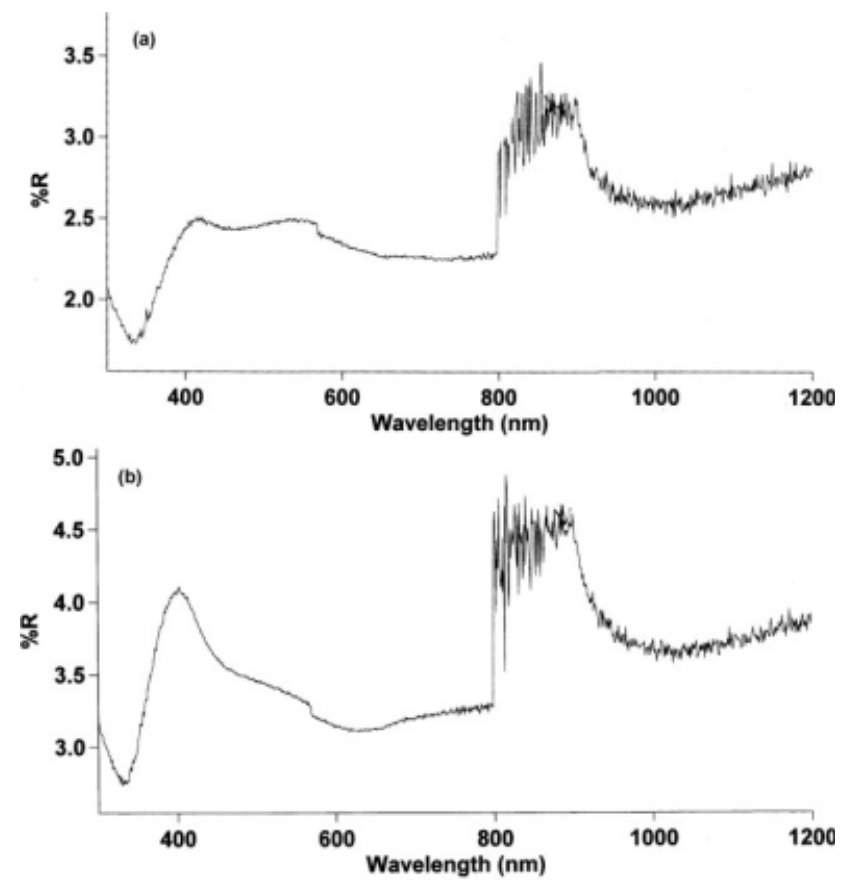

Figure 6 Reflectance $(R)$ spectra of polymers deposited onto stainless steel electrodes: (a) PPy-CAPSA and (b) P(NMePy)-CAPSA. 

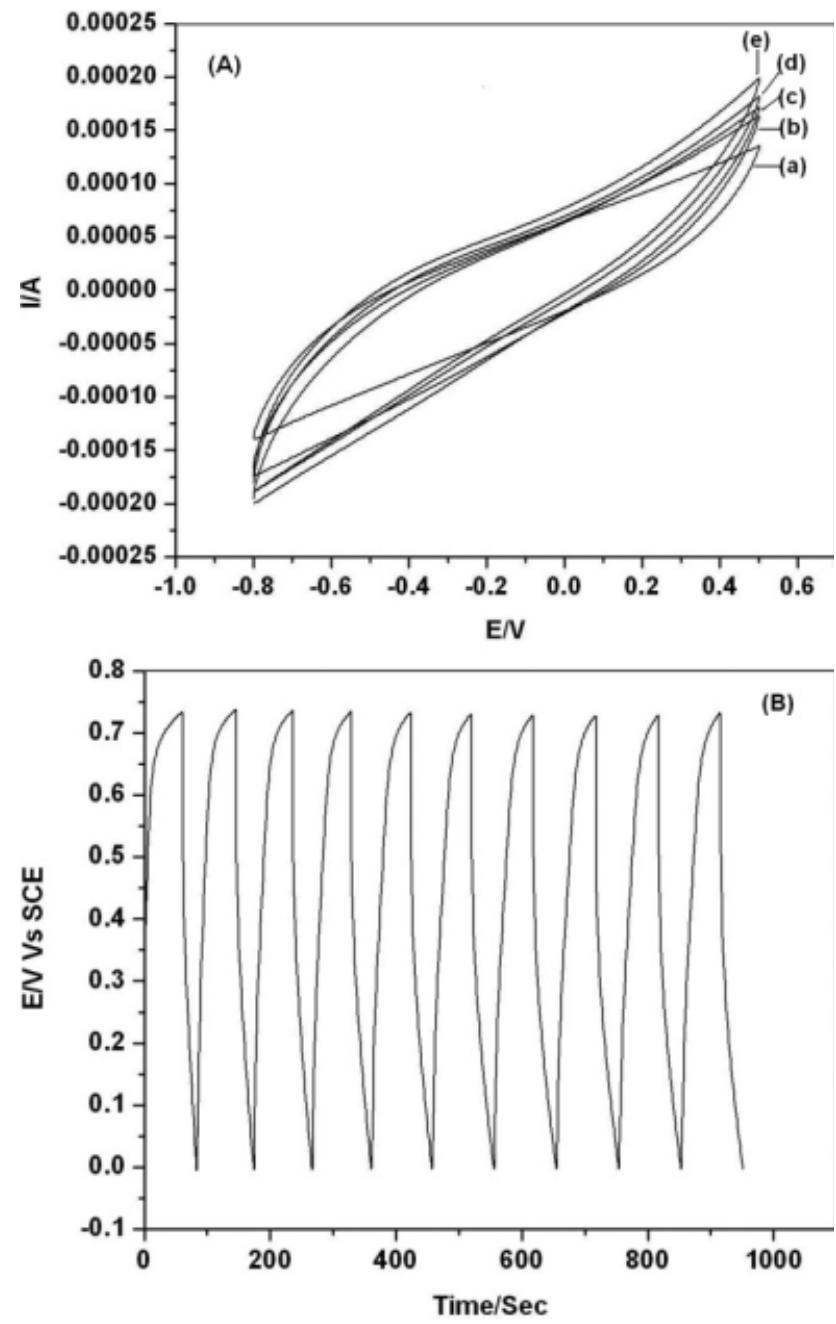

Figure 7 (A) CV of a PPy-CAPSA polymer deposited onto a $1-\mathrm{cm}^{2}$ stainless steel electrode at (a) 50, (b) 100, (c) 200, (d) 300 , and (e) $400 \mathrm{mV} / \mathrm{s}$ in a $1 \mathrm{M} \mathrm{KCl}$ solution and (B) a typical charge-discharge profile of the electrode in $1 \mathrm{M} \mathrm{KCl}$ at $0.1 \mathrm{~mA} / \mathrm{cm}^{2}$.

$1463.8 \mathrm{~cm}^{-1}$ were assigned to fundamental vibrations of pyrrole rings. ${ }^{29,30}$ The peak at 3434 $\mathrm{cm}^{-1}$ was assigned to $\mathrm{N}-\mathrm{H}$ stretching vibration from pyrrole. The reflectance spectra (Fig. 6) of the films on stainless steel electrodes exhibited bands at 421 and $533 \mathrm{~nm}$ for PPy-CAPSA and at 403 and 566 $\mathrm{nm}$ for $\mathrm{P}(\mathrm{NMePy})-\mathrm{CAPSA}$. The absorption peaks observed around $400 \mathrm{~nm}$ were assigned to the $\pi-\pi^{*}$ transition associated with the benzenoid ring. The band due to cation radicals lay between 420 and 600 $\mathrm{nm}$. The band observed near $880 \mathrm{~nm}$ was due to the charge carriers. ${ }^{31}$ After this band, the reflectance value increased up to $1200 \mathrm{~nm}$, and this suggests that the film would show a band in the infrared region due to bipolaron charge carriers. This was clearly evident from FTIR bands at 921.6 and $1207.9 \mathrm{~cm}^{-1}$. The conductivity of the PPy and $\mathrm{P}(\mathrm{NMePy})$ films polymerized on stainless steel electrodes was $3.98 \times 10^{-5}$ and $1.23 \times 10^{-5} \mathrm{~S} / \mathrm{cm}$, respectively, which suggested a lower degree of doping in $\mathrm{P}(\mathrm{NMePy})$.

Charge-discharge tests were performed on a PPy-CAPSA electrode [Fig. 7(b)]. For this purpose, the polymer was deposited for 40 cycles by the $\mathrm{CV}$ method, as described previously, to produce a uniform layer $\left(0.2 \mathrm{mg} / \mathrm{cm}^{2}\right)$ of the electroactive material. The charge-discharge curves with time showed the standard $\Lambda$ shape profile, demonstrating the linear relation [Fig. 7(b)]. The $\mathrm{CV}$ profiles of the PPy-CAPSA stainless steel electrode at various scan rates are shown in Figure $7(\mathrm{a})$. When the scan rate was increased, the current also increased. The shapes of the curves are nearly rectangular. The specific capacitance of the electrode at a scan rate of $50 \mathrm{mV} / \mathrm{s}$ [specific capacitance $=(I) /(W) \times$ $(d v / d t)]$ was about $80 \mathrm{~F} / \mathrm{g}$, which decreased to 25 $\mathrm{F} / \mathrm{g}$ when the scan rate increased to $400 \mathrm{mV} / \mathrm{s}$. $\mathrm{P}(\mathrm{NMePy})-\mathrm{CAPSA}$ showed lower values of the specific capacitance.

Electrochemical impedance spectroscopy is an important tool for the characterization of conducting polymers as it provides valuable information on charge transport phenomena, rate constants, and double-layer capacitance in porous materials. ${ }^{32,33}$ Figure 8 presents a Nyquist plot of a PPy-CAPSA stainless steel electrode in $1 \mathrm{M} \mathrm{KCl}$ electrolytes. Several features can be noted from Figure 8. First, there is a semicircle in the high-frequency range that can be attributed to a double-layer charging/discharging process. ${ }^{20}$ The internal resistance (the high-frequency

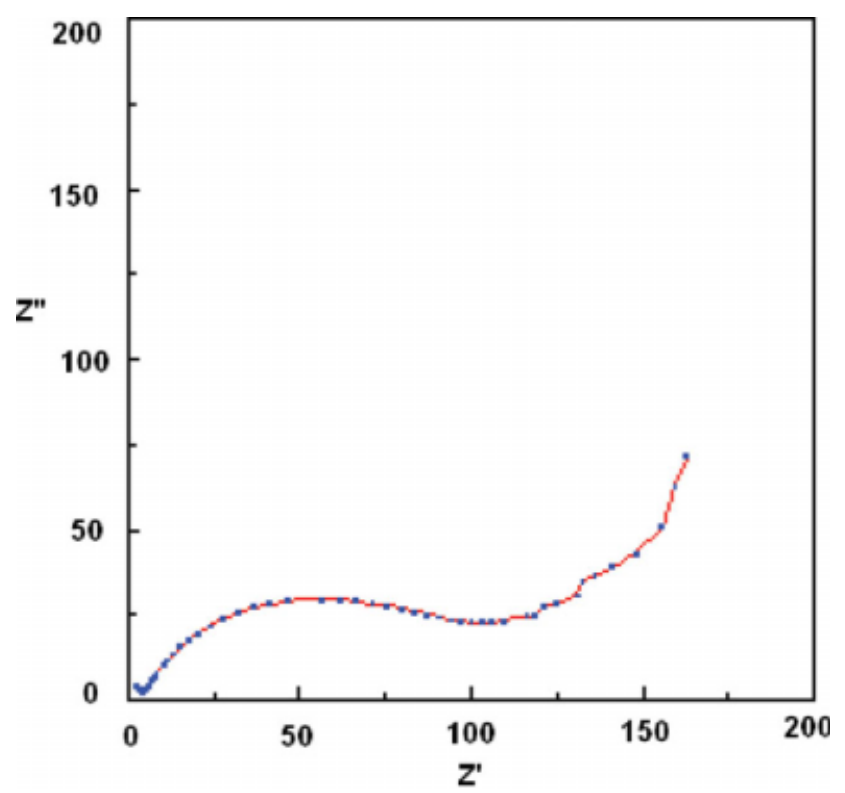

Figure 8 Impedance spectra of a PPy-CAPSA thin film on a stainless steel electrode in the alternating-current frequency range of $100 \mathrm{kHz}$ to $0.1 \mathrm{~Hz}$ at $0.0 \mathrm{~V}$ with respect to an SCE. [Color figure can be viewed in the online issue, which is available at www.interscience.wiley.com.] 


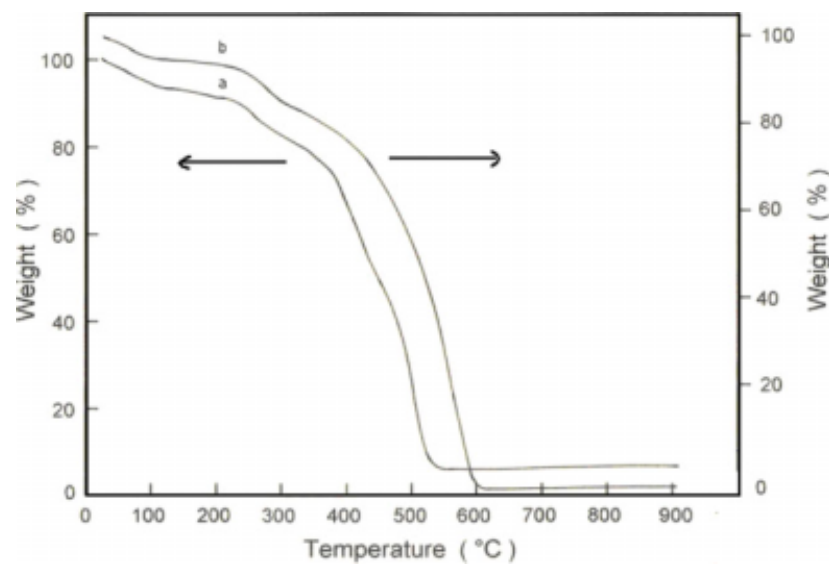

Figure 9 TGA profiles of (a) PPy-CAPSA and (b) P(NMePy)-CAPSA.

intercept of the real axis) includes the resistance of the electrolyte, the intrinsic resistance of the active material, and the contact resistance at the interface of the active material and current collector electrode. Second, in the low-frequency region, the nearly $45^{\circ}$ line is characteristic of an ion diffusion process and also reveals the porous structure of the PPy film electrode. In the low-frequency range, the slope of the impedance plot increases and tends to become purely capacitive; that is, vertical lines characterize the limiting diffusion process. ${ }^{20}$ The analysis of the impedance spectrum showed an $R_{c t}$ value of 115.08 $\Omega$, an $R_{s}$ value of $2.02 \Omega$, and a $C_{d l}$ value of $2.6 \times$ $10^{-5} \mathrm{~F}$ with a high depression angle of $34.2^{\circ}$.

The polymer films obtained by the scale-up process were tested for their stability between room temperature and $900^{\circ} \mathrm{C}$ by TGA (Fig. 9). The TGA profiles suggested that the decomposition of the materials started at 237 and $239^{\circ} \mathrm{C}$ for PPy-CAPSA and $\mathrm{P}(\mathrm{NMePy})-\mathrm{CAPSA}$, respectively, with an initial loss of moisture around $100^{\circ} \mathrm{C}$. The loss (ca. $25 \%$ ) between 230 and $390^{\circ} \mathrm{C}$ was due to the loss of the dopant CAPSA in the polymers. After these temperatures, the profiles suggested that there was continuous decomposition of the polymers until $550^{\circ} \mathrm{C}$ for PPy-CAPSA and $600^{\circ} \mathrm{C}$ for P(NMePy)CAPSA, with overall losses of 94 and 98\%, respectively.

\section{CONCLUSIONS}

The dopant used in this investigation is from a renewable source and can be useful in electrochemically synthesizing PPys with a wide range of commercial applications such as electrochemical supercapacitors and sensors. Because of its bulkiness, the in-and-out process of CAPSA from the PPy matrix is difficult. The conductivity of films doped by CAPSA is in the range of $1-4 \times 10^{-5} \mathrm{~S} / \mathrm{cm}$, sug- gesting a low degree of doping by CAPSA. The films have the usual cauliflower morphology with globular nanostructures in the range of $50-200 \mathrm{~nm}$. This polymer shows moderate pseudo-capacitance values, and these values can be improved if the morphology of the films is tailored to still lower size dimensions. CAPSA-doped PPys are stable at room temperature and start decomposing after $200^{\circ} \mathrm{C}$.

The authors thank the director of the Central Electrochemical Research Institute for his encouragement and for the creation of new instrumentation facilities. They also thank C. K. S. Pillai and his team members for their generous donation of the CAPSA sample.

\section{References}

1. Shirakawa, H.; Louis, L. J.; McDiarmid, A. G.; Chang, C. K.; Heeger, A. J. J Chem Soc Chem Commun 1977, 578.

2. Handbook of Conducting Polymers; Skotheim, T. A., Ed.; Marcel Dekker: New York, 1986; Vols. I and II.

3. Sonmez, G. J Chem Soc Chem Commun 2005, 5251.

4. Han, D. H.; Lee, H. J.; Park, S. M. Electrochim Acta 2005, 50, 3085.

5. Khomenko, V.; Frackowiak, E.; Beguin, F. Electrochim Acta 2005, 50, 2499.

6. Johanson, U.; Marandi, A.; Tamm, T. J. Electrochim Acta 2005, 50, 1523.

7. Weidlich, C.; Mangold, K. M.; Juttner, K. Electrochim Acta 2005, 50, 1547.

8. Krivan, E.; Peintler, G.; Visy, C. Electrochim Acta 2005, 50, 1529.

9. Chehimi, M. M.; Abel, M. L.; Perruchot, C.; Delamar, M.; Lascelles, S. F.; Armes, S. P. Synth Met 1999, 104, 51.

10. Azioune, A.; Siroti, F.; Tanguy, J.; Jouini, M.; Chehimi, M. M.; Miksa, B.; Slomkowski, S. Electrochim Acta 2005, 50, 1661.

11. Saoudi, B.; Despas, C.; Chehimi, M. M.; Jammul, N.; Delamar, M.; Bessiere, J.; Walcarius, A. Sens Actuators B 2002, 62, 35.

12. Raoof, J. B.; Ojani, R.; Rashid-Nadimi, S. Electrochim Acta 2004, 49, 271.

13. Khomenko, V. G.; Barsukov, V. Z.; Katashinskii, A. S. Electrochim Acta 2005, 50, 1675.

14. Ramanavicius, A.; Malinauskas, A.; Ramanaviciene, A. In Advanced Biomaterials for Medical Applications; Thomas, D. W., Ed.; Kluwer Academic: Dordrecht, 2004; p 93.

15. Hien, N. T. L.; Garcia, B.; Pailleret, A.; Deslouis, C. Electrochim Acta 2005, 50, 1747.

16. Ramanavicius, A.; Ramanaviciene, A.; Malinauskas, A. Electrochim Acta 2007, 51, 6025.

17. Geetha, S.; Rao, C. R. K.; Vijayan, M.; Trivedi, D. C. Anal Chim Acta 2006, 568, 119.

18. Conway, B. E. Electrochemical Supercapacitors-Scientific Fundamentals and Technology Applications; Kluwer Academic/Plenum: New York, 1999.

19. Hughes, M.; Chen, G. Z.; Shaffer, M. S. P.; Fray, D. J.; Windle, A. H. Chem Mater 2002, 14, 1610.

20. Wu, Q.-F.; He, K.-X.; Mi, H.-Y.; Zhang, X.-G. Mater Chem Phys 2007, 101, 369.

21. Anilkumar, P.; Jayakannan, M. Langmuir 2006, 22, 5952.

22. Anilkumar, P.; Jayakannan, M. Phys Chem C 2007, 111, 3591

23. Anilkumar, P.; Jayakannan, M. Macromolecules 2007, 40, 7311. 
24. Liu, Y.; Hwang, B.; Jian, W.; Santhanam, R. Thin Solid Films 2000, 374, 85.

25. Inganas, O.; Erlandsson, R.; Nylander, C.; Lundstrom, I. J Phys Chem Solids 1984, 45, 427.

26. Wallace, G.; Spinks, G. M.; Kane-Maguire, L. A. P.; Teasdale, P. R. Conducting Electroactive Polymers; Taylor \& Francis: Washington, DC, 2008; Chapter 3.

27. Tian, B.; Zerbi, G. J Chem Phys 1990, 92, 3892.

28. Chen, A.; Wang, H.; Li, X. J Chem Soc Chem Commun 2005, 1863.
29. Liu, J.; Wan, M. J Polym Sci Part A: Polym Chem 2000, 38, 2734.

30. Nguyen, T.; Diaz, A. Adv Mater 1994, 6, 858.

31. Geetha, S.; Trivedi, D. C. Mater Chem Phys 2004, 88, 388.

32. Bard, A. J.; Faulkner, L. R. Electrochemical Methods: Fundamentals and Applications; Wiley: New York, 1980.

33. Lasia, A. In Modern Aspects of Electrochemistry; Conway, B. E.; et al., Eds.; Kluwer Academic/Plenum: New York, 1999; Vol. 32, p 143. 